\title{
THE CREEP OF ICE SHELVES: THEORY
}

\author{
By R. H. Thomas \\ (British Antarctic Survey, Scott Polar Research Institute, Cambridge, England)
}

\begin{abstract}
Budd's expressions for strain-rate gradient along the centre line of a bounded ice shelf are shown to be applicable only to ice shelves with almost constant thickness and very small longitudinal strainrates. A general expression is derived for creep in an ice shelf where the sole restriction is that of zero shear stresses in vertical planes. This is applied to the two special cases:

(I) movement of an ice shelf restricted in at least one direction by sea-water pressure only;

(2) movement of an ice shelf flowing between roughly parallel sides.

RÉsumé. Le fluage des plateforms de glace : théorie. On montre que les expressions de Budd pour le gradient des vitesses de déformation le long de la ligne centrale d'une plateforme de glace ne sont applicables qu'aux plateformes d'épaisseur presque constante et ne présentant qu'une très petite vitesse de déformation dans le sens longitudinal. On en déduit une expression générale pour le fluage dans une plateforme de glace où l'unique restriction est celle d'un effort de cisaillement nul le long de plans verticaux. On applique cette théorie à deux cas spéciaux:

$1^{\circ}$ ) Celui d'une plateforme de glace limitée au moins dans une direction par la seule pression de l'eau de mer;

$2^{\circ}$ ) celui d'une plateforme de glace s'écoulant entre deux parois approximativement parallèles.

Zusammenfassung. Das Kriechen von Schelfeisen: Theorie. Es wird gezeigt, dass Budd's Ausdrücke für den Gradienten der Verformungsgeschwindigkeit entlang der Mittellinie begrenzter Schelfeise nur auf solche mit fast konstanter Dicke und sehr geringen longitudinalen Verformungsgeschwindigkeiten angewendet werden können. Ein allgemeiner Ausdruck wird für das Kriechen in einem Schelfeis abgeleitet, wobei die einzige Einschränkung das Verschwinden der Scherspannungen in vertikalen Ebenen ist. Dies wird auf folgende beiden Spezialfälle angewendet:

(1) Ein Schelfeis, das zumindest auf einer Seite nur von Seewasser begrenzt wird;

(2) Ein zwischen annähernd parallelen Begrenzungen fliessendes Schelfeis.
\end{abstract}

\section{THE FLOW LAW}

Laboratory studies (Steinemann, [1956]; Glen, I955; Tabor and Walker, 1970) of the steady-state creep of polycrystalline ice in uniaxial compression gave a power law relating strain-rate $\dot{\epsilon}$ and applied stress $\sigma$ :

$$
\dot{\epsilon}=K \sigma^{n}
$$

where $K$ is a temperature-dependent constant of the form $A \mathrm{e}^{-Q / R T}$ and $n$ is approximately constant $(\approx 3)$ over the stress range o. 1 to $2 \mathrm{MN} \mathrm{m}^{-2}$.

Neglecting elastic strains, Odqvist's (1934; 1966, p. 2 I) generalization to three dimensions of the uniaxial law can be written:

$$
\dot{\gamma}_{0}=\left(\tau_{0} / B_{0}\right)^{n}
$$

where $2 \dot{\gamma}_{0}^{2} / 3$ and $2 \tau_{0}^{2} / 3$ are the second invariants of the strain-rate and stress deviator tensors respectively:

$$
\begin{aligned}
& 2 \dot{\gamma}_{0}^{2} / 3=\dot{\epsilon}_{x x^{2}}+\dot{\epsilon}_{y y^{2}}+\dot{\epsilon}_{z z^{2}}+2\left(\dot{\epsilon}_{x y}{ }^{2}+\dot{\epsilon}_{x z^{2}}+\dot{\epsilon}_{y z^{2}}\right), \\
& 2 \tau_{0}^{2} / 3=\sigma_{x x^{2}}{ }^{2}+\sigma_{y y}^{\prime}{ }^{2}+\sigma_{z z^{2}}^{\prime}+2\left(\sigma_{x y}{ }^{2}+\sigma_{x z^{2}}+\sigma_{y z^{2}}\right) \text {, }
\end{aligned}
$$

where $x, y$ and $z$ are mutually perpendicular axes, $\dot{\epsilon}_{x x}$ is the strain-rate in the $x$ direction and $\sigma_{x x}^{\prime}$ is the deviatoric stress in the $x$ direction. $\dot{\gamma}_{0}$ is the effective shear strain-rate and $\tau_{0}$ is the effective shear stress. Nye (1953) proposed alternative definitions with $2 \dot{\gamma}_{0}{ }^{2} / 3$ and $2 \tau_{0}{ }^{2} / 3$ replaced by $2 \dot{\gamma}^{2}$ and $2 \tau^{2}$ so that in a pure shear experiment the shear stress is $\tau$ and the shear strain-rate is $\dot{\gamma}$. This slightly modified form of Odqvist's generalization has since been accepted in glaciological work. The constant $B_{0}$ is replaced by $B$ which can be expressed in terms of $K$ and $n$. The strain-rate in any direction $x$ then becomes:

$$
\dot{\epsilon}_{x x}=(\tau / B)^{n-1} \sigma^{\prime}{ }_{x x} / B
$$


2. The GReEP OF ICE SHELVES

\section{I. Unconfined ice shelf}

Floating ice shelves represent perhaps the simplest natural ice forms. They rest on a frictionless bed, stress conditions are uniform over large distances, and boundary conditions at the upper and lower surfaces are known. Consequently analysis of their creep behaviour avoids many of the problems associated with land glaciers. For an unconfined ice shelf of constant thickness $H$ we have zero shear stresses of the type $\sigma_{i j}$ if we choose $x$ - and $y$-axes

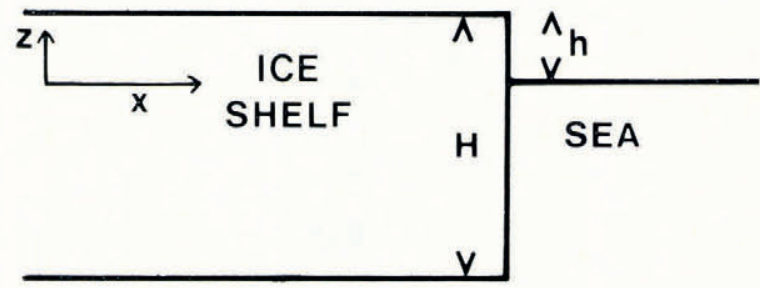

Fig. I. Longitudinal section of an ice shelf.

horizontal at sea-level and $z$-axis vertical (Fig. I). By balancing stresses in the $x$ direction summed over depth against sea-water pressure at the ice front Weertman (1957) showed that, for an ice shelf of uniform density $\rho$ and zero transverse creep

$$
\dot{\epsilon}_{x x}=(\rho g h / 4 \bar{B})^{n}
$$

where $h$ is the elevation above sea-level of the ice-shelf top surface and $\bar{B}$ is the value of $B$ averaged over depth.

\subsection{Bounded ice shelf}

Weertman's analysis predicts that the longitudinal strain-rate $\dot{\epsilon}_{x x}$ will increase rapidly with increasing ice thickness. But Budd ( I 966) reported observations on the Amery Ice Shelf showing the opposite trend with $\dot{\epsilon}_{x x}$ rapidly decreasing almost to zero as the ice thickness (and distance from the ice front) increased. The Amery Ice Shelf lies between two almost parallel flanks of land ice and Budd suggested that under these conditions Weertman's expression for an unrestricted ice shelf should not be expected to apply. Instead, part of the driving force due to the weight of ice above sea-level is used in overcoming the restraining effect of the ice-shelf margins. Consequently the ice thickness increases rapidly away from the ice front, and this feature was considered by Crary (ig66) to be responsible for overdeepening at the inland end of fjords.

Nye's velocity solution for a flat ice shelf held at its sides and deforming by laminar flow (Nye, r952) can be written

$$
V_{c}-V_{y}=\frac{2 y^{n+\mathrm{I}}}{(n+\mathrm{I}) B^{n}}\left(\frac{\partial p}{\partial x}\right)^{n}
$$

where $V_{c}$ is the velocity at the centre line of the ice shelf and $V_{y}$ is the velocity of the ice at a distance $y$ from the centre line of the ice shelf. $\partial p / \partial x$ is the pressure gradient (assumed to be independent of $y$ ) along the ice shelf. Budd substituted

$$
\frac{\partial \bar{\sigma}_{x x}}{\partial x}=\frac{\partial}{\partial x}\left\{\frac{\mathrm{I}}{H} \int_{b}^{s} \sigma_{x x} \mathrm{~d} z\right\},
$$


(where $z$ is measured in the vertical direction, $b$ and $s$ refer to the lower and upper surfaces of the ice shelf, and bars denote values averaged over depth) for $\partial p / \partial x$ in Equation (5) to obtain an expression for the strain-rate gradient along the centre line. However, in this situation $\partial p / \partial x$ is the stress gradient averaged over depth

$$
=\frac{\mathrm{I}}{H} \int_{b}^{s} \frac{\partial \sigma_{x x}}{\partial x} \mathrm{~d} z
$$

so that Budd's expression applies only to ice shelves of constant thickness. Furthermore Equation (5) is based on the assumption that $\dot{\epsilon}_{x x}$ is zero whereas Budd reported large values of longitudinal strain-rate on the Amery Ice Shelf.

In Budd (I969, p. I I 5 and I 23) a general expression was derived for $\partial\left(H \bar{\sigma}^{\prime}{ }_{x x}\right) / \partial x$ where $\bar{\sigma}^{\prime} x x$ is the longitudinal deviatoric stress and is $\frac{1}{2}\left(\bar{\sigma}_{x x}-\bar{\sigma}_{z z}\right)$ for zero transverse strain. With the assumption that the effective shear stress can be written as $\bar{\sigma}_{x x}^{\prime}$ Budd then obtained an expression involving the longitudinal strain-rate gradient:

$$
\frac{\partial\left(\bar{B} \bar{H} \dot{\epsilon}_{\left.x x^{1 / n}\right)}\right.}{\partial x} \approx \frac{1}{2}\{\rho g \bar{H}(\omega+f)\}
$$

where $\omega$ is the surface slope and $f$ is the boundary friction coefficient defined in terms of the shear stress at the perimeter of a cross-section and a shape factor. Here the bars denote averages taken over the section.

For ice shelves, Budd (1969, p. $13^{8}$ ) reduced Equation (6) to:

$$
\frac{\partial\left(\bar{B} \dot{\epsilon}_{x x^{\mathrm{I}} / n}\right)}{\partial x} \approx \frac{\mathrm{I}}{2}\left\{\rho g \omega+\frac{\text { shear stress at sides }}{\text { half width }}\right\}
$$
with the implicit assumption that terms involving $\partial H / \partial x$ on the left-hand side of Equation (6)
are insignificant,

or

$$
\left|\frac{\partial H}{\partial x}\right| \ll\left|\frac{H}{n \dot{\epsilon}_{x x}} \cdot \frac{\partial \dot{\epsilon}_{x x}}{\partial x}\right| .
$$
Using data for G I on the Amery Ice Shelf given in Thomas (I973) we find $\partial H / \partial x \approx 2 \times \mathrm{IO}^{-3}$
and

$$
\left|\frac{H}{n \dot{\epsilon}_{x x}} \cdot \frac{\partial \dot{\epsilon}_{x x}}{\partial x}\right| \approx 2 \times \mathrm{IO}^{-3}
$$

and in this instance the assumption is certainly not warranted.

Furthermore for "Weertman" creep, Equation (7) reduces to

$$
\frac{\partial\left(\bar{B}_{x x^{\mathrm{I}} / n}\right)}{\partial x}=\frac{1}{2} \rho g \omega
$$

whereas differentiation of Equation (4) gives

$$
\frac{\partial\left(\bar{B} \dot{\epsilon}_{x x^{\mathrm{I}} / n}\right)}{\partial x}=\frac{1}{4} \rho g \omega .
$$

Thus Equation (7) is limited in its application to the case where

$$
\left|\frac{\partial H}{\partial x}\right| \ll\left|\frac{H}{n \dot{\boldsymbol{\epsilon}}_{x x}} \cdot \frac{\partial \dot{\boldsymbol{\epsilon}}_{x x}}{\partial x}\right|
$$

which in general implies $\partial H / \partial x \rightarrow 0$ and the ice shelf is of almost uniform thickness.

In the next section we shall derive a general expression for creep in an ice shelf where the sole restriction is that of zero shear stresses in the $x z$ and $y z$ planes. 


\section{General expression for ice-Shelf Greep}

We choose rectangular axes with the $x$-axis at sea-level in the direction of ice movement and $z$-axis upwards (Fig. I). The symbols to be used are listed below:

$\sigma_{j k} \quad j, k=x, y, z ; j=k:$ direct stress; $j \neq k:$ shear stress

$\sigma_{j k}^{\prime}$ stress deviator $=\sigma_{j k}-\delta p ; p=$ hydrostatic pressure; $\delta=\mathrm{I}$ when $j=k ; \delta=0$ when $j \neq k$

$\dot{\epsilon}_{j k} \quad$ strain-rate $=\frac{1}{2}\left(\partial u_{j} / \partial k+\partial u_{k} / \partial j\right) ; u=$ velocity

$H$ ice-shelf thickness

$h$ ice-shelf surface elevation

$\rho$ density.

The subscripts $\mathrm{i}$ and $\mathrm{w}$ refer to ice and sea-water respectively. All densities are assumed independent of $x, y$ and $z$ in order to simplify the equations. However, at appropriate points, equations in squared brackets are included to incorporate ice density as a function of $z$.

For quasi-static creep the equilibrium conditions are:

$$
\begin{aligned}
& \frac{\partial \sigma_{x x}}{\partial x}+\frac{\partial \sigma_{x y}}{\partial y}+\frac{\partial \sigma_{x z}}{\partial z}=0, \\
& \frac{\partial \sigma_{y y}}{\partial y}+\frac{\partial \sigma_{y x}}{\partial x}+\frac{\partial \sigma_{y z}}{\partial z}=0, \\
& \frac{\partial \sigma_{z z}}{\partial z}+\frac{\partial \sigma_{z x}}{\partial x}+\frac{\partial \sigma_{z y}}{\partial y}=\rho_{\mathrm{i}} g .
\end{aligned}
$$

We make the following assumptions:

(a) Ice is incompressible and hence

$$
\dot{\epsilon}_{x x}+\dot{\epsilon}_{y y}+\dot{\epsilon}_{z z}=0 \text {. }
$$

(b) The ice shelf is in hydrostatic equilibrium so that

$$
(H-h) \rho_{\mathrm{w}}=H \rho_{\mathrm{i}} \quad\left[=\int_{b}^{s} \rho_{\mathrm{i}}(z) \mathrm{d} z\right] \text {. }
$$

(c) Zero shear strains in the $x z$ and $y z$ planes. This means that velocity and strainrates are independent of $z$.

(d) The generalized flow law (Equation (3)) holds for ice.

Together with assumptions (a) and (c) this means that

$$
\sigma_{x x}^{\prime}+\sigma_{y y}^{\prime}+\sigma_{z z}^{\prime}=\sigma_{x z}=\sigma_{y z}=0 .
$$

Equation (10) now becomes:

$$
\frac{\partial \sigma_{z z}}{\partial z}=\rho_{\mathrm{i}} g .
$$

Field results give values of $\dot{\epsilon}_{x x}, \dot{\epsilon}_{y y}$ and $\dot{\epsilon}_{x y}$ at some point $\mathrm{P}(x, y, z)$, on the ice-shelf surface, and we can express each in terms of $\dot{\epsilon}_{x x}$ :

$$
\dot{\epsilon}_{y y}=\alpha \dot{\epsilon}_{x x}, \quad \dot{\epsilon}_{x y}=\beta \dot{\epsilon}_{x x}, \quad \dot{\epsilon}_{z z}=-(\mathrm{I}+\alpha) \dot{\epsilon}_{x x} .
$$

In general $\alpha$ and $\beta$ are functions of $x$ and $y$ but, from assumption (c), they are independent of $z$. Except in the special cases summarized at the end of section $3.1, \alpha$ and $\beta$ are deduced from measurements of the strain-rate components.

$$
\begin{aligned}
& \text { From the flow law we also have that the ratio } \dot{\epsilon}_{j k} / \sigma^{\prime}{ }_{j k} \text { is constant at any point, so } \\
& \qquad \sigma_{y y}^{\prime}=\alpha \sigma^{\prime}{ }_{x x}, \quad \sigma^{\prime}{ }_{x y}=\beta \sigma^{\prime}{ }_{x x}, \quad \sigma_{z z}^{\prime}=-(\mathrm{I}+\alpha) \sigma^{\prime}{ }_{x x}, \\
& \text { and } \sigma_{x x}^{\prime}+(\mathrm{I}+\alpha) \sigma^{\prime}{ }_{x x}=\left(\sigma_{x x}-p\right)-\left(\sigma_{z z}-p\right), \\
& \text { or } \quad \sigma_{x x}^{\prime}=\frac{\sigma_{x x}-\sigma_{z z}}{2+\alpha} .
\end{aligned}
$$$$
\text { or }
$$ 
Using Equation (I I) and neglecting atmospheric pressure we also have

$$
\sigma_{z z}=\rho_{\mathrm{i}} g(z-h) \quad\left[=-g \int_{z}^{h} \rho_{\mathrm{i}}(z) \mathrm{d} z\right] \text {. }
$$

So, integrating Equation (12) over $z$ gives:

where

$$
\begin{aligned}
\int_{b}^{s} \sigma^{\prime}{ }_{x x} \mathrm{~d} z & =\frac{\mathrm{I}}{2+\alpha} \int_{-(H-h)}^{h}\left\{\sigma_{x x}-\rho_{\mathrm{i}} g(z-h)\right\} \mathrm{d} z \\
& =\left(\frac{1}{2} \rho_{\mathrm{i}} g H^{2}-F\right) /(2+\alpha)
\end{aligned}
$$

$$
F \equiv-\int_{b}^{s} \sigma_{x x} \mathrm{~d} z
$$

is the total force opposing the movement of a unit vertical section at $\mathrm{P}$.

$$
\left[\frac{1}{2} \rho_{\mathbf{i}} g H^{2} \quad \text { becomes } \quad g \int_{b}^{s} \int_{z}^{s} \rho_{\mathbf{i}}(z) \mathrm{d} z \mathrm{~d} z \quad \text { if density is a function of } z \text {. }\right]
$$

In order to obtain a solution for the strain-rate we next express the effective shear stress $\tau$ in terms of $\sigma^{\prime} x x$.

By definition:

$$
\begin{aligned}
& 2 \tau^{2}=\sigma_{x x^{2}}{ }^{2}+\sigma_{y y^{2}}{ }^{2}+\sigma_{z z^{2}}{ }^{2}+2 \sigma_{x y^{2}}+2 \sigma_{x z^{2}}+2 \sigma_{y z^{2}} \\
& =2\left(\mathrm{I}+\alpha+\alpha^{2}+\beta^{2}\right) \sigma_{x x^{2}} \\
& \tau=+\left(\mathbf{I}+\alpha+\alpha^{2}+\beta^{2}\right)^{\frac{1}{2}}\left|\sigma^{\prime}{ }_{x x}\right| \text {. }
\end{aligned}
$$

and

The flow law

$$
\dot{\epsilon}_{x x}=\left(\frac{\tau}{B}\right)^{n-1} \frac{\sigma_{x x}^{\prime}}{B}
$$

now becomes:

$$
\left|\dot{\epsilon}_{x x}\right|=\left(\mathrm{I}+\alpha+\alpha^{2}+\beta^{2}\right)^{(n-1) / 2}\left\{\frac{\left|\sigma_{x x}^{\prime}\right|}{B}\right\}^{n}
$$

with the sign of $\dot{\epsilon}_{x x}$ determined by that of $\sigma^{\prime} x x$.

Thus:

$$
\dot{\epsilon}_{x x}=\frac{\sigma_{x x}^{\prime}}{\left|\sigma_{x x}^{\prime}\right|}\left|\dot{\epsilon}_{x x}\right|
$$

and using the assumption (c) we can write:

$$
\left|\int_{b}^{s} \sigma^{\prime}{ }_{x x} \mathrm{~d} z\right|=\frac{\left|\dot{\epsilon}_{x x}\right|^{1 / n}}{\left(\mathrm{I}+\alpha+\alpha^{2}+\beta^{2}\right)^{(n-1) / 2 n}} \int_{b}^{s} B \mathrm{~d} z .
$$

Comparing Equations ( $\mathrm{I}_{3}$ ) and ( $\left.\mathrm{I}_{5}\right)$ :* $^{*}$

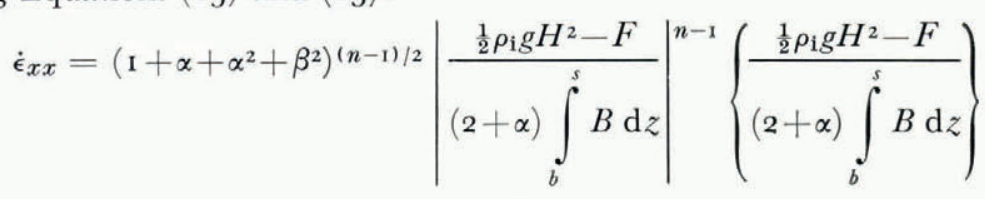

*When $\alpha=-2$ we also have $\frac{1}{2} \rho_{i} g H=F / H$ and Equation (16) is insoluble. 
which, for convenience, we write:

where

$$
\dot{\epsilon}_{x x}=\frac{\dot{\epsilon}_{x x}}{\left|\dot{\epsilon}_{x x}\right|} \theta\left|\frac{\frac{1}{2} \rho_{1} g H-F / H}{\bar{B}}\right|^{n}
$$

where

$$
\theta=\left(\mathrm{I}+\alpha+\alpha^{2}+\beta^{2}\right)^{(n-1) / 2} /|2+\alpha|^{n}
$$

$$
\bar{B}=\frac{\mathrm{I}}{H} \int_{b}^{s} B \mathrm{~d} z
$$

and the sign of $\dot{\epsilon}_{x x}$ is determined by that of

$$
\left\{\frac{\frac{1}{2} \rho_{\mathrm{i}} g H-F / H}{2+\alpha}\right\} \text {. }
$$

Note that with $\beta=0$ the term $(2+\alpha) \theta /|2+\alpha|$ reduces to

$$
\left\{\left(1+x+\alpha^{2}\right) /(2+\alpha)^{2}\right\}^{(n-1) / 2} /(2+\alpha)
$$

which can be shown to be equal to $\mathrm{I} / \phi$, where $\phi$ is Budd's "transverse strain function" (Budd, เ 969 , p. 126).

Equation (I6) is of little use unless we can evaluate $F$, so we shall consider two special cases which approximate conditions in actual ice shelves.

\section{I. Ice-shelf movement restricted in at least one direction by sea-water pressure only}

By choosing the $x$-axis to coincide with this direction, $F$ becomes the total force exerted by the sea on a unit vertical section of ice shelf:

$$
\begin{aligned}
F_{\mathrm{w}}= & -\int_{-(\dot{H}-h)}^{0} \rho_{\mathrm{w}} g z \mathrm{~d} z=\frac{(H-h)^{2}}{2} \rho_{\mathrm{w}} g \\
= & \frac{1}{2} \rho_{\mathrm{i}} g\left(\frac{\rho_{\mathrm{i}}}{\rho_{\mathrm{w}}}\right) H^{2} .
\end{aligned}
$$

Equation (I6) becomes:

$$
\begin{aligned}
\dot{\epsilon}_{x x} & =\theta\left\{\frac{\rho_{\mathrm{i}} g h}{2 \bar{B}}\right\}^{n} \\
& {\left[=\theta\left\{\frac{g}{\bar{B} H}\left(\int_{b}^{s} \int_{z}^{s} \rho_{\mathrm{i}}(z) \mathrm{d} z \mathrm{~d} z-\frac{\mathrm{I}}{2} \rho_{\mathrm{w}}(H-h)^{2}\right)\right\}^{n}\right] . }
\end{aligned}
$$

With $\alpha=\beta=0$, Equations (I 7) and (I8) reduce to Weertman's (I957) expressions (Equation (4) is one of these) for an ice shelf free to creep in one horizontal direction only. The expression for an ice shelf (or iceberg) uniformly spreading in all directions is obtained by setting $\alpha=\mathrm{I}$ and $\beta=\mathrm{o}$, giving:

$$
\dot{\epsilon}_{x x}=3^{-(n+\mathrm{1}) / 2}\left\{\frac{\rho_{\mathrm{i}} g h}{2 \bar{B}}\right\}^{n} .
$$

These equations will not apply very near the ice front where shear stresses are induced in the $x z$ plane by unbalanced hydrostatic pressure at the ice cliff.

\subsection{Ice shelf flowing between approximatelv parallel sides}

Consider a vertical element of unit width taken parallel to the $x$-axis at a distance $y$ from 
the central line of the ice shelf (Fig. 2). In this case $F$ is the force due to water pressure $F_{\mathrm{w}}$ plus that due to shear past the sides $F_{\mathrm{s}}$. So Equation (16) becomes:

$$
\dot{\epsilon}_{x x}=\frac{\dot{\epsilon}_{x x}}{\left|\dot{\epsilon}_{x x}\right|} \theta\left|\frac{\rho_{\mathrm{i}} g h}{{ }_{2 \bar{B}}}-\frac{F_{\mathrm{s}}}{H \bar{B}}\right|^{n} \text {. }
$$

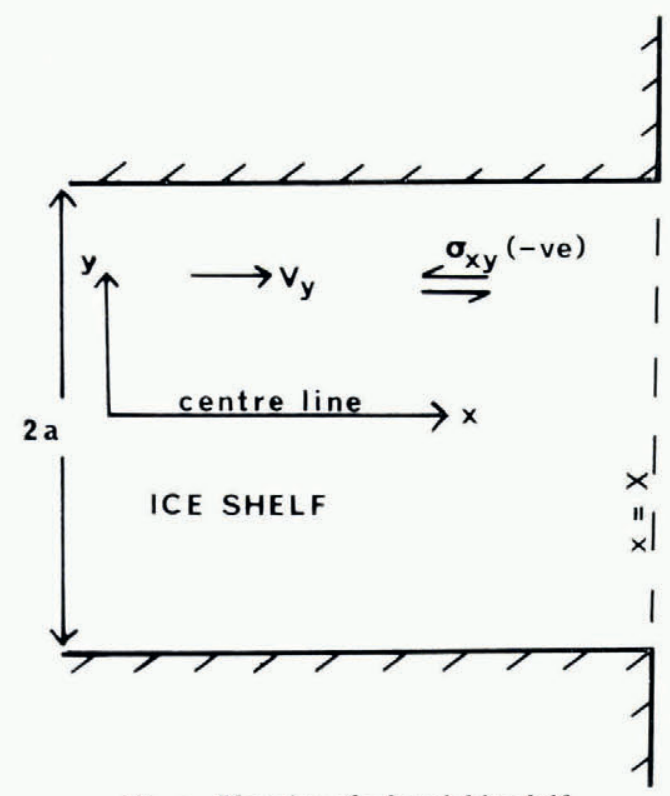

Fig. 2. Plan view of a bounded ice shelf.

The net shear stress acting up-stream on the element at some point $(x, y, z)$ is $-\left(\partial \sigma_{x y} / \partial y\right)$ and the total up-stream force due to shear on the entire section between $x=x$ and $x=X$ (the point at which the ice shelf leaves its protective margins) becomes:

$$
F_{\mathrm{s}}=-\int_{x}^{x} \int_{b}^{s} \frac{\partial \sigma_{x y}}{\partial y} \mathrm{~d} z \mathrm{~d} x .
$$

To proceed further we make the additional assumptions

(e) $\partial \sigma_{x y} / \partial y$ is independent of $y$, then

$$
\frac{\partial \sigma_{x y}}{\partial y}=\frac{\sigma_{x y}}{y}
$$

(f) $\sigma_{x y}$ at the sides of the ice shelf averaged over $z$ reaches some limiting value which is independent of $x$ and equal to $\bar{\tau}_{\mathrm{S}}$ so that

$$
\int_{b}^{s} \frac{\partial \sigma_{x y}}{\partial y}=\frac{\bar{\tau}_{\mathrm{s}} H}{a}
$$

where $a$ is the half-width of the ice shelf.

Equation (2I) then becomes:

$$
F_{\mathrm{s}}=-\bar{\tau}_{\mathrm{s}} \int_{x}^{X} \frac{H \mathrm{~d} x}{a}
$$


and

$$
\dot{\epsilon}_{x x}=\frac{\dot{\epsilon}_{x x}}{\left|\dot{\epsilon}_{x x}\right|} \theta\left(\frac{\mathrm{I}}{\bar{B}}\left\{\frac{\rho_{\mathrm{i}} g h}{2}+\frac{\bar{\tau}_{\mathrm{s}}}{H} \int_{x}^{X} \frac{H}{a} \mathrm{~d} x\right\}\right)^{n} .
$$

With $\bar{\tau}_{\mathrm{s}}$ equal to some appropriate "yield stress", say $10^{5} \mathrm{~N} \mathrm{~m}^{-2}$ we can solve this equation using values of $H, a$ and $h$ measured at different points along the ice shelf.

We can also obtain a solution in terms of the shear strain-rate $\dot{\epsilon}_{x y}$ :

$$
\dot{\epsilon}_{x y}=\left(\frac{\tau}{B}\right)^{n-1} \frac{\sigma_{x y}}{B},
$$

and with

$$
\begin{aligned}
\sigma_{x x}^{\prime} & =\left(\frac{\mathrm{I}}{\beta}\right) \sigma_{x y}, \\
\tau & =+\left(\mathrm{I}+\alpha+\alpha^{2}+\beta^{2}\right)^{\frac{1}{2}} \sigma_{x y} / \beta .
\end{aligned}
$$

Substituting for $\tau$ in Equation (24) gives:

$$
\left|\dot{\epsilon}_{x y}\right|=\left(\frac{\mathrm{I}+\alpha+\alpha^{2}+\beta^{2}}{\beta^{2}}\right)^{(n-1) / 2}\left|\frac{\sigma_{x y}}{B}\right|^{n} .
$$

From assumption (c), $\dot{\epsilon}_{x y}$ is independent of $z$, so we can write:

and, with

$$
\left|\dot{\epsilon}_{x y}\right|=\left(\frac{\mathrm{I}+\alpha+\alpha^{2}+\beta^{2}}{\beta^{2}}\right)^{(n-1) / 2}\left|\frac{\bar{\sigma}_{x y}}{\bar{B}}\right|^{n},
$$

$$
\begin{gathered}
\bar{\sigma}_{x y}=\frac{\bar{\tau}_{\mathrm{s}} y}{a}, \\
\left|\dot{\epsilon}_{x y}\right|=\left(\frac{\mathrm{I}+\alpha+\alpha^{2}+\beta^{2}}{\beta^{2}}\right)^{(n-1) / 2}\left|\frac{\bar{\tau}_{\mathrm{s}} y}{a \bar{B}}\right|^{n} .
\end{gathered}
$$

If values of the strain-rate components are measured at several different values of $y$, Equation (25) can be used to find $n$. The correct value of $n$ is that which gives the best straight line for a plot of $\dot{\epsilon}_{x y}$ versus

$$
\left\{\left(\mathrm{I}+\alpha+\alpha^{2}+\beta^{2}\right) / \beta^{2}\right\}^{(n-1) / 2}(y / a)^{n}
$$

assuming $\bar{B}$ is approximately independent of $x$ and $y$.

We can write Equation (25)

$$
\bar{\tau}_{\mathrm{S}}=-\frac{a \bar{B}|\beta|^{(n-1) / n}\left|\dot{\epsilon}_{x y}\right|^{\mathrm{I} / n}}{y\left(\mathrm{I}+\alpha+\alpha^{2}+\beta^{2}\right)^{(n-\mathrm{I}) / 2 n}} .
$$

Thus, measurements of strain-rate at some point at distance $y$ from the centre line can be used to evaluate $\bar{\tau}_{\mathrm{s}}$ in terms of $\bar{B}$ if we know $n$. This value can then be substituted for $\bar{\tau}_{\mathrm{S}}$ in Equation (23) which then becomes:

$$
\left|\dot{\epsilon}_{x x}\right|=\frac{\left(\mathrm{I}+\alpha+\alpha^{2}+\beta^{2}\right)^{(n-1) / 2}}{\bar{B}^{n}|2+\alpha|^{n}}\left|\frac{\rho_{\mathrm{i}} g h}{2}-\frac{a \bar{B}\left|\beta_{\mathrm{I}}\right|^{(n-1) / n}\left|\dot{\epsilon}_{x y}\right|^{\mathrm{I} / n}}{H y\left(\mathrm{I}+\alpha_{\mathrm{I}}+\alpha_{\mathrm{I}}{ }^{2}+\beta_{\mathrm{i}}^{2}\right)^{(n-1) / 2 n}} \int_{x}^{X} \frac{H}{a} \mathrm{~d} x\right|^{n}
$$

where $\dot{\epsilon}_{x y}, \alpha_{\mathrm{I}}$ and $\beta_{1}$, need not necessarily be measured at the same point as $\dot{\epsilon}_{x x}, \alpha$ and $\beta$. The sign of $\dot{\epsilon}_{x x}$ is decided by that of $\left(\frac{1}{2} \rho_{i} g H-F / H\right) /(2+\alpha)$ so Equation (27) can be written

$$
\bar{B}=\left\{\frac{\left|\dot{\epsilon}_{x x}\right|^{\mathrm{I} / n}(2+\alpha) \dot{\epsilon}_{x x}}{\left(\mathrm{I}+\alpha+\alpha^{2}+\beta^{2}\right)^{(n-1) / 2 n}\left|\dot{\epsilon}_{x x}\right|}+\frac{\left|\dot{\epsilon}_{x y}\right|^{1 / n}\left|\beta_{\mathrm{I}}\right|^{(n-1) / n} a \int_{x}^{X}(H / a) \mathrm{d} x}{H y\left(\mathrm{I}+\alpha_{\mathrm{I}}+\alpha_{\mathrm{I}}{ }^{2}+\beta_{\mathrm{I}}{ }^{2}\right)^{(n-\mathrm{I}) / 2 n}}\right\}^{-\mathrm{I}} \frac{\rho_{\mathrm{i}} g h}{2}
$$


If $\dot{\epsilon}_{x x}$ and $\dot{\epsilon}_{x y}$ are measured at the same point this reduces to:

$$
B=\frac{\left(\mathrm{I}+\alpha+\alpha^{2}+\beta^{2}\right)^{(n-1) / 2 n} \rho_{\mathrm{i}} g h}{2\left|\dot{\epsilon}_{x x}\right|^{\mathrm{I} / n}\left\{(2+\alpha) \frac{\dot{\epsilon}_{x x}}{\left|\dot{\epsilon}_{x x}\right|}+\frac{|\beta| a}{y H} \int_{x}^{X} \frac{H \mathrm{~d} x}{a}\right\}}
$$

This expression can be used at any point on the ice shelf, except on the centre line where both $\beta$ and $y$ are zero.

In a companion paper (Thomas, 1973) the equations derived above will be used to interpret available ice-shelf data.

\section{AGKNOWLEdGements}

I thank the British Antarctic Survey for sponsoring this work, Dr W. F. Budd for helpful discussions, and members of the Scott Polar Research Institute for reading and improving the manuscript.

MS. received 5 February 1972 and in revised form 31 August 1972

\section{REFERENCES}

Budd, W. F. 1966. The dynamics of the Amery Ice Shelf. Fournal of Glaciology, Vol. 5, No. 45, p. 335-58.

Budd, W. F. 1969. The dynamics of ice masses. ANARE Scientific Reports. Ser. A(IV). Glaciology. Publication No. 108.

Crary, A. P. 1966. Mechanism of fiord formation indicated by studies of an ice-covered inlet. Geological Society of America. Bulletin, Vol. 77, No. 9, p. 911-29.

Glen, J. W. i 955 . The creep of polycrystalline ice. Proceedings of the Royal Society, Ser. A, Vol. 228, No. I 15 , p. $519-38$.

Nye, J. F. 1952. The mechanics of glacier flow. Journal of Glaciology, Vol. 2, No. 12, p. 82-93.

Nye, J. F. 1953. The flow law of ice from measurements in glacier tunnels, laboratory experiments and the Jungfraufirn borehole experiment. Proceedings of the Royal Society, Ser. A, Vol. 2 19, No. I I39, p. 477-89.

Odqvist, F. K. G. 1934. Plasticitetsteori med tillämpningar. Stockholm, Ingenjörsvetenskapsakademien.

Odqvist, F. K. G. 1966. Mathematical theory of creep and creep rupture. Oxford, Clarendon Press.

Steinemann, S. [1956.] Flow and recrystallization of ice. Union Géodésique et Géophysique Internationale. Association Internationale d'Hydrologie Scientifique. Assemblée générale de Rome, 1954, Tom. 4, p. 449-62.

Tabor, D., and Walker, J. C. F. 1970. Creep and friction of ice. Nature, Vol. 228, No. 5267, p. 137-39.

Thomas, R. H. 1973. The creep of ice shelves: interpretation of observed behaviour. Fournal of Glaciology, Vol. 1 2, No. 64 , p. $55-70$.

Weertman, J. 1957. Deformation of floating ice shelves. Fourna lof Glaciology, Vol. 3, No. 21, p. $3^{8-42 .}$ 